\title{
The mechanics of milling of germanium for IR applications
}

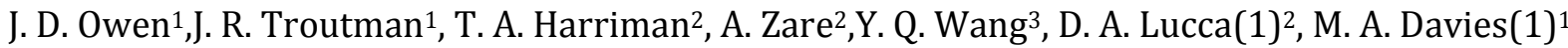 \\ ${ }^{1}$ Center for Precision Metrology, Department of Mechanical Engineering and Engineering Science, \\ University of North Carolina at Charlotte, Charlotte, NC, USA \\ ${ }^{2}$ School of Mechanical and Aerospace Engineering, Oklahoma State University, Stillwater, OK, USA \\ ${ }^{3}$ Division of Materials Science and Technology, Los Alamos National Laboratory, Los Alamos, NM, USA
}

\begin{abstract}
Freeform germanium optics produced by single crystal diamond milling are important for infrared (IR) imaging applications.However the mechanics of interrupted cutting of germaniumis not fully understood. This paper presents new findings from cutting experiments including: (1) uninterrupted orthogonal cutting and (2) interruptedflycutting of germanium. Forces are measured and the cutting mechanics are correlated with surface and subsurface measurements performed with: (1) atomic force microscopy, (2) confocal Raman spectroscopy, and (3) channeling Rutherford backscattering spectrometry. These fundamental results guide parameter choice for more complex freeform ball milling of optics for IR applications ranging from surveillance to medical imaging.
\end{abstract}

Ultra-precision milling, Optical materials, Subsurface damage

\section{Introduction}

Freeform optics with no axis of rotational invariance either on or off the part [1] allow near arbitrary redirection of light in three dimensions. Enabled by advances in optical simulation and design software, coupled with advances in computer aided manufacturing technology, freeform optics are poised to radically change optical systems [2-3]. Longer wavelength applications such as infrared (IR) imaging have more relaxed manufacturing specifications, and thus diamond multi-axis milling [4] is a viable path for the production of freeform IR optics. However, the IRtransparent materialsused for these optics(e.g., $\mathrm{Ge}, \mathrm{Si}$, chalcogenide glass, $\mathrm{ZnSe}$, etc.)are brittle. Single crystal diamond (SCD) turning of these materials to produce an optical quality surface free of brittle fracture has been achieved in materials such as glass [5-7] and Ge [8-10]. However, manufacturing of freeform optics often requires a highly interrupted cutting process, such as ball milling [3-4]. For the production of robust freeform IR optics, a better understanding of interrupted cutting of brittle materials and the effect on surface and subsurface integrity is needed.

In this paper, we focus on the interrupted machining of single crystal Ge, an important IR material. Previous research has shown that interrupted machining of $\mathrm{Ge}$ [3] can produce an optical quality finish under geometric conditions different from those reported in the turning literature[9]. To investigate the effect of an interrupted cut on the nature of the surface and subsurface produced in Ge, simplified cutting experiments were conducted. The nature of the surface and subsurface was measured with atomic force microscopy (AFM), confocal Raman spectroscopy and channeling Rutherford backscattering spectrometry (RBS). Forces were measured in (1) uninterrupted orthogonal turning and (2) interrupted flycutting. The cutting mechanics werecorrelated with the surface and subsurface measurements. Understanding the operative physical mechanisms of interrupted machining of brittle materials and their effect on surface and subsurface integrity could expand the suite of materials that can be successfully freeform milled.

\section{Description of Experiments}

All cutting experiments were conducted with SCD tools on a Moore 350 FG ultra-precision machine tool with single crystal (111) Ge workpieces. Four experimental configurations were used: (1) orthogonal cutting, (2) round-nosed turning, (3) roundnosed flycutting, and (4) ball endmilling. These configurations allow for the dynamic effects of interrupted cutting, such as short time-of-contact between the tool and workpiece to be examined separately from cutting geometry. In this paper we focus mainly on configurations (1) and (3). In particular, the surface and subsurface of specimens generated by interrupted flycutting under different conditions are measured with AFM, confocal Raman spectroscopy and channeling RBS.

\subsection{Orthogonal Cutting}

The orthogonal turning arrangement is shown in Fig. 1. A "dead sharp" tool with $0^{\circ}$ rake, $7^{\circ}$ clearance, and $60^{\circ}$ included angle was tilted with an adapter plate to effectively produce a $-25^{\circ}$ rake angle and suppress brittle fracture $[9,10]$. The tool machined the outer diameter of a $38 \mathrm{~mm}$ disk (Fig. 1(b)). The chip width was $200 \mu \mathrm{m}$, the uncut chip thickness $(h)$ was varied from $0.010 \mu \mathrm{m}$ to $10 \mu \mathrm{m}$. The surface speed for all experiments was held constant at $4 \mathrm{~m} / \mathrm{s}$ and forces were measured by mounting the tool to a Kistler 9256-C1 miniature cutting force dynamometer that had a natural frequency of approximately $5 \mathrm{kHz}$.

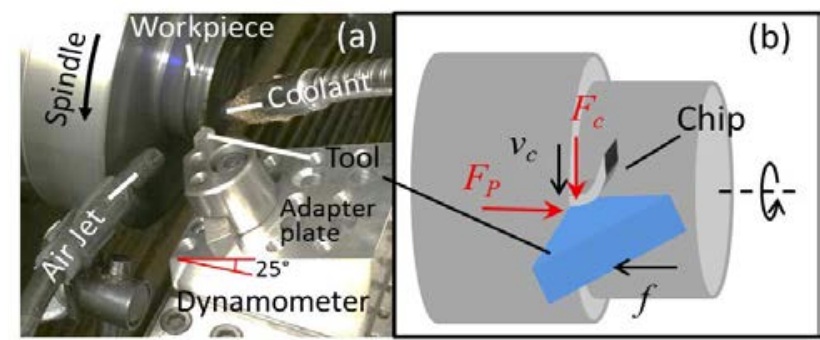

Figure 1.(a) Orthogonal turning setup and (b) schematic. 


\subsection{Specimen Preparation by Flycutting}

In diamond turning single crystal brittle materials, the direction of the cutting force relative to the crystal orientation changes the cutting mechanics. Nakasuji et al. [8] showed that when face turning the (111) surface of Ge there is a three-fold symmetry in the crystal response that can be observed in the specimens, with a greater propensity for surface fracture when the crystal is loaded along the $[1 \overline{2} 1],[11 \overline{2}]$, and[211] directions. Accounting for this, flycutspecimens that could be directly compared to turned specimens under the same cutting conditions were prepared.Asreceived mechanically polished $25 \mathrm{~mm}$ wafers with an initial average surface roughness $(\mathrm{Ra})$ of approximately $1.4 \mathrm{~nm}$ were face turned with a $1 \mathrm{~mm}$ radius SCD tool having a $-25^{\circ}$ rake angle and a $7^{\circ}$ clearance angle at a feedrate $(f)$ of $3 \mu \mathrm{m} / \mathrm{rev}$ and a depth of cut of $5 \mu \mathrm{m}$. This produced a tri-lobed pattern with regions of increased fracture consistent withNakasujiet al. [8] (blue in Fig. 2(a)). Three specimens $8 \mathrm{~mm}$ in diameter and $1 \mathrm{~mm}$ thick were diced from each wafer with an orientation flat aligned along the cutting directions that produced the least surface fracture (Fig. 2(b)). The specimens were then flipped and flycut on the asreceived polished surface in a nearly constant direction aligned with the orientation flat. This was done by mounting the same SCD tool used for face turning on a $100 \mathrm{~mm}$ diameter flycutter (Fig. 2(c)). The depth of cut was $5 \mu \mathrm{m}$ and $f$ was varied from 0.5 to $9.0 \mu \mathrm{m} / \mathrm{rev}$. Thus, the main difference between the flycut samples at $f$ equal to $3.0 \mu \mathrm{m} / \mathrm{rev}$ was the interruption in cut. The surface speed for all experiments was held constant at $4 \mathrm{~m} / \mathrm{s}$. The specimens were mounted to a custom vacuum chuck and dynamometer to measure forces for all cutting conditions.

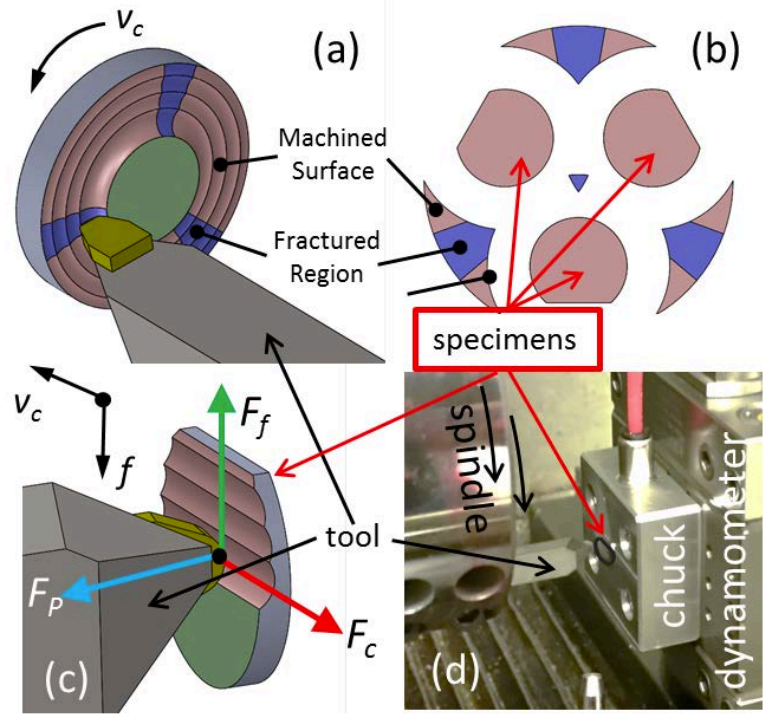

Figure 2. (a) Round-nosed turning, (b) singulated specimens for flycutting, (c) round-nosed flycuttingand force definitions, and (d) round-nosed flycutting setup.

\subsection{Surface and Subsurface Characterization}

A commercial Bruker AFM operating in tapping mode was used to examine the surface topography and measure the average surface roughness (Ra) and average maximum roughness height (Rz) of the flycut specimens. Confocal Raman spectroscopy was used to obtain a measure of lattice disorder present in the near surface of the flycut specimens. A backscattering configuration was used, along with a frequency doubled Nd:YAG laser $(\lambda=532 \mathrm{~nm})$ and a $100 \mathrm{x} / 0.9 \mathrm{NA}$ microscope objective. The laser power was minimized to avoid heating of the specimen. A piezoelectrically driven three-axis stage was used to scan the excitation spot over a $50 \times 50 \mu \mathrm{m}^{2}$ area of each flycut specimen. Each scanned area was composed of 150 by 150 individual spectra. To quantify the
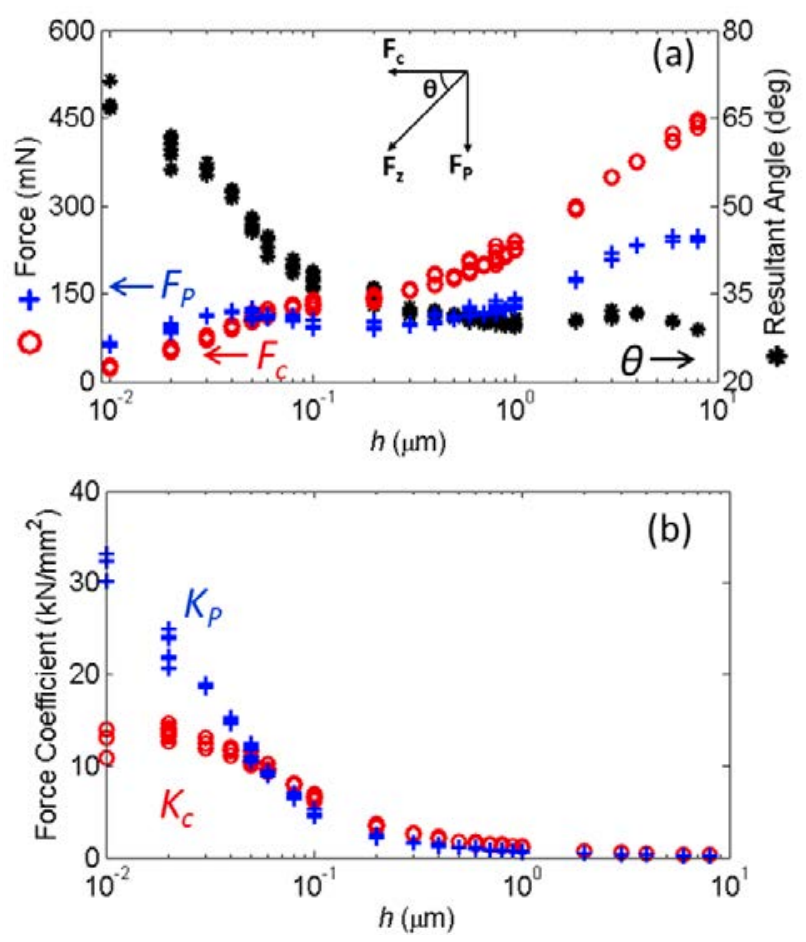

Figure 3. Semi-log plots of (a) the measured forces, angle $\theta$ of $\mathbf{F}_{\mathbf{z}}$ and(b) force coefficients as a function ofuncut chip thickness.

spatial variations in Raman response, the microscope software was used to perform Lorentzian curve fittings of the Ge Raman mode for each individual spectrum. As a second measure of resulting lattice disorder, RBS under channeling conditions was performed. A collimated beam of $2 \mathrm{MeV}^{4} \mathrm{He}^{+}$ions with a spot size of approximately $1 \times 1 \mathrm{~mm}^{2}$ was directed at the specimens which were aligned with their (111) surface normal to the beam axis and held in a chamber at $4-5 \times 10^{-7}$ Torr. The backscattered particles were collected with a solid state detector with a solid angle of $2.5 \mathrm{msr}$ positioned $13^{\circ}$ off the beam axis. Spectra of backscatter particles vs. backscattered energy were collected to quantify the surface response.

\section{Results and Discussion}

\subsection{Force Measurements}

\subsubsection{Orthogonal Turning}

Cutting forces $\left(F_{c}\right)$ and thrust forces $\left(F_{p}\right)$ measuredduring orthogonal turning are shown in Fig. 3(a). Also shown is the angle $(\theta)$ of the resultant force vector $\left(\mathbf{F}_{\mathbf{z}}\right)$. As discussed by Lucca et al. [10],for large $h, \mathbf{F}_{\mathbf{z}}$ was at a constant $\theta$ of approximately $30^{\circ}$ fromthe cutting direction. This orientation results ina tensile stress state in the near surface which promotessurface fracture. As his decreasedbelow $200 \mathrm{~nm}, \mathbf{F}_{\mathbf{z}}$ is seen to rotate toward the workpiece surface normalreaching a maximum $\theta$ of approximately $70^{\circ}$ forh $=0.01 \mu \mathrm{m}$. This rotation of $\mathbf{F}_{\mathbf{z}}$ causes a rotation of the tensile stress field out of the workpiece surface resulting in a more compressive state of stress in the cutting region, which suppresses brittle fracture. It is expectedthat specimens created with an $h \leq 200 \mathrm{~nm}$ should exhibit a decrease in the amount of surface fracture. Both the behaviorof $\theta$ and the expected hof the transition to a fractured surface (at anhbelow $200 \mathrm{~nm}$ )is consistent with the literature $[9,10]$. Figure 3(b) shows the cutting force coefficients $\left(K_{c}\right.$ and $\left.K_{p}\right) . K_{c}$ represents the energy per unit volume of material removed or specific cutting energy. Below $200 \mathrm{~nm}, K_{c}$ increasessignificantly, also consistent with a transition from a brittle-fracture dominated mode of material removal to one dominated by plastic deformation. 


\subsubsection{Round-nosed Flycutting}

Figure 4 shows the measured $F_{c}$ (red line) and $F_{p}$ (blue line) and resultant cutting force vector angle $\theta$ (black line) as a function of $f$ for flycutting. A smaller $f$ correlates to a smallermaximum uncut chip thickness (see inset). Similar to orthogonalturning, for large $f, \mathbf{F}_{\mathbf{z}}$ is generally aligned with the cutting direction $\left(\theta<40^{\circ}\right)$. When $f$ was below $3 \mu \mathrm{m} / \mathrm{rev}, \mathbf{F}_{\mathbf{z}}$ was seen to rotate toward the workpiece surface normal. The shaded regions in Fig. 4 are mechanistic force predictions calculated by integrating the differential force components $\left(K_{c} d A\right.$ and $\left.K_{p} d A\right)$ around the tool nose as shown in the inset, using the $K_{c}$ and $K_{p}$ determined from the orthogonal cutting experiments (Fig. 3(b)). The widths of the shaded regions result from the uncertainties in $K_{c}$ and $K_{p}$.It is unclear why the measured and predicted $F_{p}$ does not compare as well as the measured and predicted $F_{c}$.

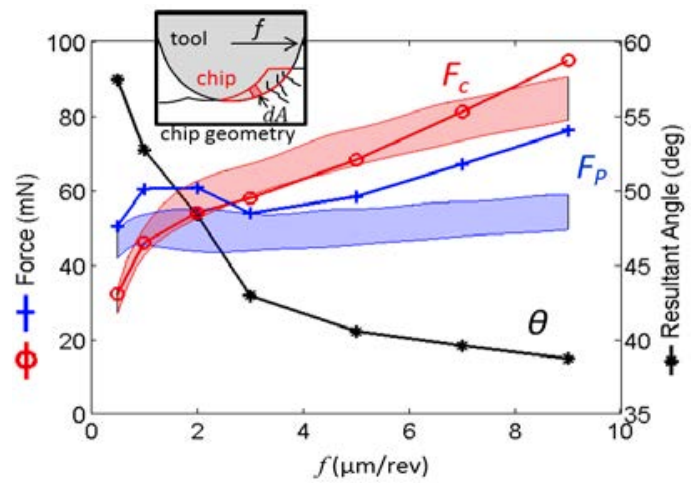

Figure 4.Measured and predicted forces as a function of $f$ for roundnosed flycutting, along with the angle $\theta$ of $\mathbf{F}_{\mathbf{z}}$.

\subsection{Surface and Subsurface Characterization}

For the surfaces prepared by round-nosedflycutting, the surface topography and roughness was measured with AFM. Figure 5 shows the surface topography measured over $5 \times 5 \mu \mathrm{m}^{2}$ areas. Surfaces created with $f \leq 2 \mu \mathrm{m} / \mathrm{rev}$ showed very few if any signs of fractureas evidenced by the small number of pits.For $f=3 \mu \mathrm{m} / \mathrm{rev}$, there was a notable increase in the number of surface pits, indicating surface fracture. With a further increase in $f$, the number,areal size, and depth of the pits was seento increase. This behavior is further illustrated by the $\mathrm{Ra}$ and $\mathrm{Rz}$ surface roughness values, shown in Table 1 . These values are the average of three individual measurements on different regions of the specimen surface. Again, surfaces created with $f \leq 2 \mu \mathrm{m} / \mathrm{rev}$ had similar surface roughnesswhile the surface created with $f=3 \mu \mathrm{m} / \mathrm{rev}$ showed an increase,which is consistent with the onset of fracture. Further increase in $f$ led to a continual increase in the surface roughness.

The subsurface damage of the surfaces prepared by round-nosed flycutting was investigated with a combination of Raman spectroscopy and channeling RBS. A typical Raman spectrum of

Table 1.Summary of the surface roughness values, Raman mode widths, and channeling RBS integrated intensities of the round-nosed flycut specimens.

\begin{tabular}{|c|c|c|c|c|}
\hline $\begin{array}{c}f \\
(\mu \mathrm{m} / \mathrm{rev})\end{array}$ & $\begin{array}{c}\mathrm{Ra} \\
(\mathrm{nm})\end{array}$ & $\begin{array}{c}\mathrm{Rz} \\
(\mathrm{nm})\end{array}$ & $\begin{array}{c}\text { Raman FWHM } \\
\left(\mathrm{cm}^{-1}\right)\end{array}$ & $\begin{array}{c}\text { RBS Integrated } \\
\text { Intensity } \\
(\# / \mu \mathrm{C} / \mathrm{msr})\end{array}$ \\
\hline 0.5 & 1.0 & 16.1 & $7.14 \pm 0.40$ & 181 \\
\hline 1 & 1.2 & 16.2 & $7.32 \pm 0.41$ & 416 \\
\hline 2 & 1.8 & 26.6 & $7.79 \pm 0.64$ & 355 \\
\hline 3 & 2.3 & 64.6 & $8.04 \pm 0.68$ & 385 \\
\hline 5 & 6.5 & 127.7 & $9.02 \pm 1.02$ & 708 \\
\hline 7 & 14.2 & 181.2 & $9.87 \pm 1.32$ & 1098 \\
\hline 9 & 40.9 & 342.4 & $10.28 \pm 1.58$ & -- \\
\hline
\end{tabular}

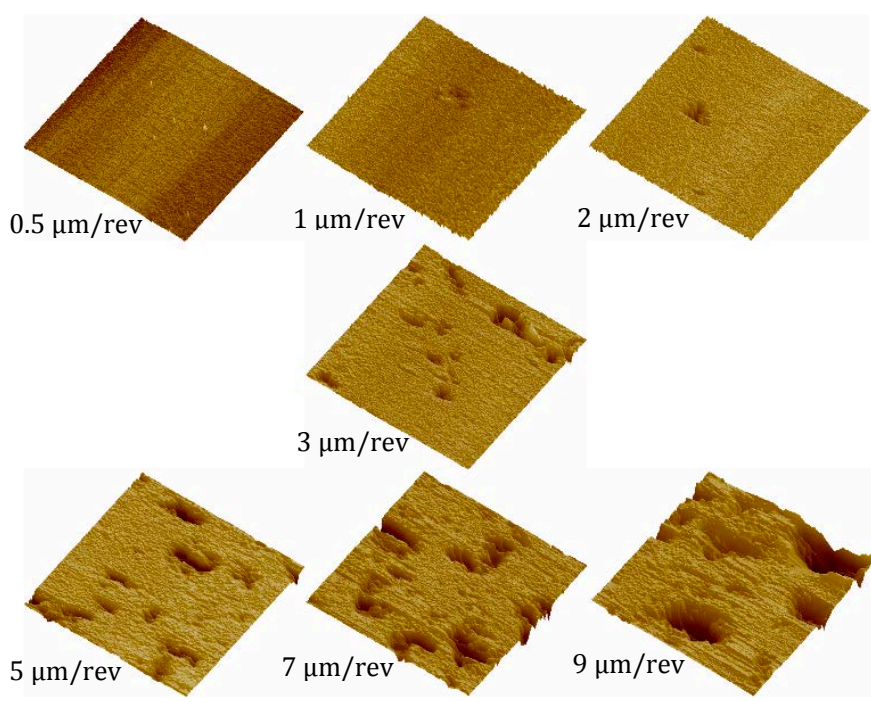

Figure 5. AFM images of the flycut surfaces created with a range of $f$ measured over $5 \times 5 \mu^{2}$ areas. The height scale is 100,200 , and $600 \mathrm{~nm}$ for the surfaces prepared by $f \leq 2 \mu \mathrm{m} / \mathrm{rev}, f=3 \mu \mathrm{m} / \mathrm{rev}$, and $f \geq 5 \mu \mathrm{m} / \mathrm{rev}$, respectively.

theas-received Ge is shown in Fig. 6 where the only peak observed was the triply degenerate Ge mode centered near $300 \mathrm{~cm}^{-1}$. The inset of Fig. 6 shows the detail of the Ge mode from surfaces created with an $f=0.5 \mu \mathrm{m} / \mathrm{rev}$ (solid) and $f=9 \mu \mathrm{m} / \mathrm{rev}$ (dashed). There was a slight shift of the mode center to higher wavenumbers observable with the higher $f$, which is an indication of a slightly more compressive residual stress [11]. Additionally there was a noticeable increase in the full-width at half-maximum (FWHM) of the mode. Changes in the FWHM can be used as a qualitative measure of crystal quality, with disorder and/or damage resulting in a broadening of the Raman mode [12]. Average FWHM values and standard deviations for all surfaces are summarized in Table 1 . With increasing $f$ there is an increase in the average value of the FWHM, which indicates an increasing amount of subsurface damage. The standard deviation of the FWHM also increased with $f$ showing an increased spatial variation of the subsurface damage.

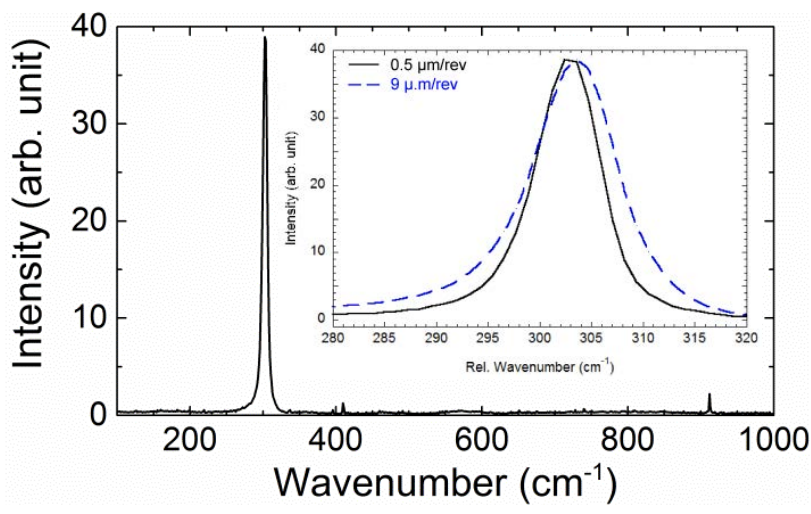

Figure 6.A typical Raman spectrum of Ge with the inset showing details of the surfaces created with $0.5 \mu \mathrm{m} / \mathrm{rev}$ (solid) and $9 \mu \mathrm{m} / \mathrm{rev}$ (dashed).

A quantitative measure of near surface quality can be made using RBS under channeling conditions. $\mathrm{MeV}$ ions directed at an aligned crystal backscatter due to direct encounters with atoms on the surface, and also as a result of near surface lattice disorder. In a channeling experiment, the number of backscattered ions as a function of their backscattered energy is collected. If the disordered layer is thin $(<1 \mu \mathrm{m})$ a surface peak in the 
backscattered spectrum occurs. It can be shown from first principles that the integrated intensity of the surface peak (the number of backscattered ions normalized by the charge collected and the solid angle of the detector) is directly proportional to the number of displaced atoms at the surface $/ \mathrm{cm}^{2}$ [13]. The values of the integrated intensities of the backscattered surface peak for the flycut specimens are summarized in Table 1 . The calculated uncertainty was approximately $10 \%$. The values indicate that the surface created with $f=0.5 \mu \mathrm{m} / \mathrm{rev}$ had the highest near surface quality, surfaces created with $f=1,2$, and $3 \mu \mathrm{m} / \mathrm{rev}$ had a slightly lower quality but were indistinguishable from each other, and the surfaces created with $f=5 \mu \mathrm{m} / \mathrm{rev}$ and $f=7 \mu \mathrm{m} / \mathrm{rev}$ each had progressively more damage. The condition of the surface created with $f=9 \mu \mathrm{m} / \mathrm{rev}$ was such that channeling conditions could not be achieved. The condition of the surface (both in terms of increased surface roughness and increased near surface lattice disorder)was below the crystal quality necessary for channeling conditions to be achieved.

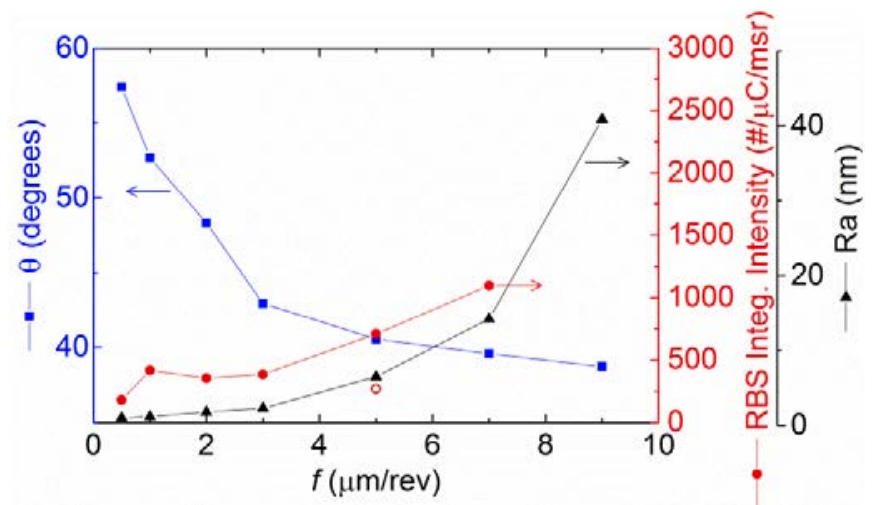

Figure 7.Round-nosed flycutting resultant force angle $\theta$, channeling RBS integrated intensity, and Ra surface roughness, each as a function of $f$. The open circle is the RBS integrated intensity of the ball endmilled specimen.

Figure 7 shows the Ra surface roughness, the integrated intensity of the channeling RBS surface peak, and the angle $\theta$ of the resultant force vector $\mathbf{F}_{\boldsymbol{z}}$, eachas a function of $f$. At large $f$ (and therefore $h$ ), a highly fractured surface is observed, resulting in a high surface roughness and high lattice disorder. This is consistent with the low values of $\theta$ indicating a resultant force vector principally in the direction of cutting. For $f \leq 3 \mu \mathrm{m} / \mathrm{rev}$, thereis little to no difference in the measured surface roughness and subsurface damage observed. This is consistent with the observed rotation of the resultant force vector toward the surface normal and a resulting reduction in the subsurface tensile stress field responsible for fracture at higher $\theta$.

Since the production of freeform Ge optics requires the more practical process of SCD ball endmilling, channeling was also performedon a ball milled surface and compared to the flycut specimens. Ball endmilling was performedwith a $1 \mathrm{~mm}$ radius, single-flute, $-25^{\circ}$ rake angle SCD diamond tool with its axis oriented at $45^{\circ}$ in the plane perpendicular to the direction of the feedrate. The surface was raster milled with a depth of cut of $100 \mu \mathrm{m}$, a stepover of $36 \mu \mathrm{m}$, and a feedrate of $5 \mu \mathrm{m} / \mathrm{rev}$. The maximum uncut chip thickness was $\sim 580 \mathrm{~nm}$, which was comparable to theflycut specimen at $f=5 \mu \mathrm{m} / \mathrm{rev}(\sim 500 \mathrm{~nm})$. The channeling RBS result for the ball-milled specimen (shown in Fig. 7 as the open red circle) indicates substantially lower damage. While the geometric complexity of ball milling versus flycutting precludes a direct comparison, one major difference between the two operations is the time of contact between the tool and workpiece: 1-2 ms for the flycut specimen compared to $0.1 \mathrm{~ms}$ for the ballmilled specimen. This indicates that further investigation of the effect of interrupted cutting on cutting mechanics and surface quality in brittle materials is warranted.

\section{Conclusions}

For the orthogonal cutting experiments a rotation of the cutting forcevector $\mathbf{F}_{\mathbf{z}}$ toward the workpiece surface normalat lower $h$, was observed, consistent with previously reported results. A similar trend was found for round-nosed flycutting.Force coefficients measured from orthogonal cutting were used to predict forces for more geometrically complex flycutting.For surfaces flycut with $f>3 \mu \mathrm{m} / \mathrm{rev}$, AFM measurements indicated a highly fractured surface, resulting in a high surface roughness. Both Raman spectroscopy and channeling RBS results also indicated high lattice disorder. This is consistent with the low values of $\theta$ indicating a resultant force vector principally in the direction of cutting. For $f \leq 3 \mu \mathrm{m} / \mathrm{rev}$, little to no difference in the measured surface roughness and subsurface damage was observed. This is consistent with the observed rotation of the resultant force vector toward the surface normal and a resulting reduction in the subsurface tensile stress field responsible for fracture at higher $\theta$.

\section{Acknowledgements}

This research was partially supported by the NSF I/UCRC Center for Freeform Optics (IIP-1338877 and IIP-1338898),NSF grants CMMI-1437225 and CMMI-1437232, and grants from the II-VI Foundation. This work was performed, in part, at the Center forIntegrated Nanotechnologies, a U.S. Department of Energy,Office of Basic Energy Sciences user facility at Los AlamosNational Laboratory (Contract DE-AC52-06NA25396) andSandia National Laboratories (Contract DE-AC0494AL85000).The assistance of Tim Jen with the channeling experiments is gratefully acknowledged.

\section{References}

[1] Fang FZ, Zhang XD, Weckenman A, Zhang, GX, Evans C (2013) Manufacture and measurement of freeform optics, CIRP Annals - Manufacturing Technology62(2):823846

[2] Thompson KP, Rolland JP (2012) Freeform optical surfaces: A revolution in imaging optical design. Optics and Photonics News 23(6):30-35.

[3] Dutterer BS, Lineberger JL, SmiliePJ, Hildebrand DS, Harriman TA, Davies MA, Suleski TJ, Lucca DA (2014) Diamond milling of an Alvarez lens in germanium. Precision Engineering 38:398-408.

[4] Owen J, Davies MA, Schmidt D, Urruti E (2015)On the ultra-precision diamond machining of chalcogenide glass, CIRP Annals - Manufacturing Technology64(1):113116.

[5] Giovanola, JH, Finnie, I (1980) On the machining of glass. Journal of Materials Science 15:2508-2514.

[6] Donaldson RR, Syn CK, Taylor JS, Riddle RA (1987) Chip science: A basic study of the single point turning process. Thrust area report: Eng. Res. and Dev., LLNL UCRL53868-87:6.12-15

[7] Puttick KE, Rudman MR, Smith KJ, Franks A, Lindsey K (1989) Single-point diamond machining of glass. Proceedings of the Royal Society of London A, Mathematical, Physical \& Engineering Sciences 426(1870):19-30.

[8] Nakasuji T, Kodera S, Hara S, Matsunage H, Ikawa N, Shimada S (1990) Diamond turning of brittle materials for optical components. CIRP Annals - Manufacturing Technology 39(1):89-92.

[9] Blake PN, Scattergood RO (1990) Ductile-regime machining of germanium and silicon.Journal of the American Ceramic Society 73(4): 949-957.

[10] Lucca DA, Chou P, and Hocken RJ (1998) Effect of tool edge geometry on the nanometric cutting of Ge.CIRP Annals - Manufacturing Technology 47(1): 475-478.

[11]Sparks RG, Paesler MA(1988) Micro-Raman analysis of stress in machined silicon and germanium. Precision Engineering 10(4):191-198.

[12]Tiong KK, Amirtharaj PM, Pollak FH, Aspnes DE (1984) Effects of $\mathrm{As}^{+}$ion implantation on the Raman spectra of GaAs: "Spatial correlation" interpretation. Applied Physics Letters 44:122-124.

[13] Lucca DA, Wetteland CJ, Misra A, Klopfstein MJ, Nastasi M, Maggiore CJ, Tesmer JR (2004) Assessment of subsurface damage in polished II-VI semiconductors by ion channeling. Nuclear Instruments and Methods in Physics Research B 219-220:611617. 